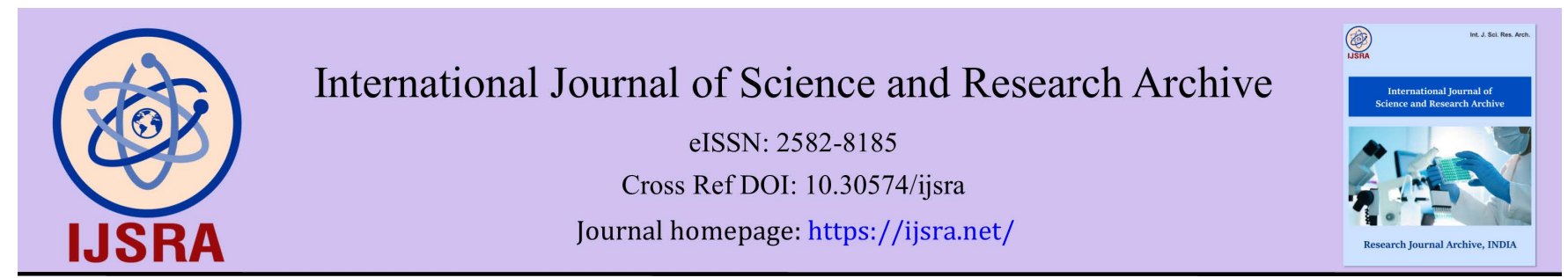

(RESEARCH ARTICLE)

Check for updates

\title{
Application of Riau local entomopathogen fungi Beauveria bassiana toward Spodoptera litura pest and plants growth red chili
}

\author{
Hapsoh, Desita Salbiah *, Isna Rahma Dini and Johanna Yosefin BR Tobing \\ Department of Agrotechnology, Faculty of Agriculture, Universitas Riau, Pekanbaru, Indonesia.
}

International Journal of Science and Research Archive, 2021, 03(01), 130-135

Publication history: Received on 30 May 2021; revised on 04 August 2021; accepted on 06 August 2021

Article DOI: https://doi.org/10.30574/ijsra.2021.3.1.0093

\begin{abstract}
Red chili is a horticultural crop that is widely cultivated commercially. The need for red chili is increasing, in accordance with the increasing variety of types of food that use red chili as a raw material. Pest attacks on red chili plants are an obstacle in red chili cultivation. Spodoptera litura is a red chili pest that can cause yield reductions of up to $80 \%$. Control using the Riau local entomopathogenic fungi Beauveria bassiana is an effort to control S. litura using environmentally friendly materials. This study aims to determine the effect of the application of the Riau local entomopathogenic fungi B. bassiana to contol S. litura pests and the growth of red chili plants. The research was carried out at the Plant Pest Laboratory and Experimental Garden, Faculty of Agriculture, Riau University from July to August 2020. This study was designed in a completely randomized design with five treatments, namely the concentration of Riau local Riau $B$. bassiana 20 gl-1 water, 25 gl-1 water, 30 gl-1 water, 35 gl-1 water and 40 gl-1 water and four replications to obtain 20 experimental units. The results showed that the concentration of Riau local B. bassiana 30 gl-1 of water containing a conidia density of $4.1 \times 10^{8} \mathrm{con} . \mathrm{ml}^{-1}$ was a concentration that affected $S$. litura pests and chili plant growth by causing the intensity of $S$. litura pests which could be categorized as lower at $4.15 \%$ and can cause a peak in larval death on the fourth day after application.
\end{abstract}

Keywords: Beauveria bassiana; Spodoptera litura; Capsicum annum; Riau local entomopathogenic

\section{Introduction}

Red chili (Capsicum annum L.) is a horticultural crop that is widely cultivated commercially. The need for red chili is increasing, in accordance with the increasing variety of types of food that use red chili as a raw material. The increasing demand for red chili plants needs to be balanced with an increase in red chili production.

Red chili production in Riau Province in 2017 was 15,813.4 tons with a harvested area of 2,236 ha, and in 2018 it decreased to $1,732.39$ tons with a harvested area of 2,309 ha [1]. The decrease in red chili production was caused by $S$. litura attack.

S. litura pests attack red chili plants in the vegetative and generative phases. Spodoptera litura causes defoliation, at a severe level $S$. litura eats up the entire leaf and leaves only the leaf bones, thus disrupting the photosynthetic ability of plants [2].

The control of $S$. litura pests on red chili plants is generally done by using chemical insecticides, continuous use of chemical insecticides can cause resistance, resurgence, increased residues carried with crop yields, destruction of natural enemies and environmental pollution.

\footnotetext{
* Corresponding author: Desita Salbiah

Department of Agrotechnology, Faculty of Agriculture, Universitas Riau, Pekanbaru, Indonesia.

Copyright (C) 2021 Author(s) retain the copyright of this article. This article is published under the terms of the Creative Commons Attribution Liscense 4.0.
} 
Spodoptera litura pest control using bioinsecticides is an effort that can be done to reduce the use of chemical insecticides. The Riau local entomopathogenic fungi $B$. bassiana is a bioinsecticide that has a wide host range, easy application, can be applied to various phases of insect life, is safe for the environment and does not interfere with the survival of natural enemies [3].

Nurani et al [4] stated that the entomopathogenic fungi B. bassiana at a concentration of 30 g.l-1 was able to control $S$. litura pests with a mortality of $75 \%$ with a conidia density of $1 \times 10^{7}$ con.ml ${ }^{-1}$. The Riau local Riau B. bassiana fungi was able to control the pod borer Maruca testualis with a mortality of $86 \%$ at a concentration of 30 g.l $\mathrm{l}^{-1}$ water with a conidia density of $5.12 \times 10^{4} \mathrm{con} . \mathrm{ml}^{-1}$ [5]. Steinhaus [6] declare that entomopathogenic fungi can be categorized as biopesticides if they are successful in controlling $72 \%-95 \%$ of insect pests.

\section{Material and methods}

\subsection{Preparation of Research Media}

The research was carried out at the Plant Pest Laboratory and Experimental Garden, Department of Agrotechnology, University of Riau from July to Agust 2020. The research was carried out experimentally using a completely randomized design consisting of 5 treatments and 4 replications, obtained 20 experimental units with each treatment being an application. concentration of Riau local entomopathogenic fungi B. bassiana 20 g.l-1 water, 25 g.l $l^{-1}$ water, 30 g.l $l^{-1}$ water,

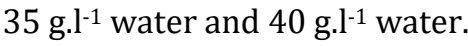

\subsection{Provision of Armyworm Caterpillars (Spodoptera litura)}

Spodoptera litura larvae were taken from the papaya plant at Experimental Garden, Faculty of Agriculture, Riau University and brought to the Plant Pest Laboratory. Larvae are kept in a jar with a diameter of $15 \mathrm{~cm}$ and a height of 7 $\mathrm{cm}$ and given fresh spinach leaves as food. Spinach leaves are changed every day until the larvae become pupae. The pupae were transferred to a jar with a diameter of $18 \mathrm{~cm}$ and a height of $20 \mathrm{~cm}$ filled with sawdust and maintained until they became imago. Imago is fed with a $10 \%$ concentration of honey solution by dipping it with cotton and hanging it in a jar. The side of the jar is given a rough tissue to place the eggs in. The egg groups on the tissue are transferred to a 13 $\mathrm{cm} \times 9 \mathrm{~cm}$ jar. Larvae are reared until they reach third instar and are ready to be used as test insects.

\subsection{Provision of Riau local Beauveria bassiana}

The soil used comes from the rhizosphere of the red chili plant in Langsat Permai Village, Bunga Raya District, Siak Regency, Riau Province. The isolation of B. bassiana was carried out by the insect bait method using fifth instar larvae of Tenebrio molitor. T. molitor suspected of being infected with B. bassiana was transferred to filter paper and incubated for seven days. B. bassiana was isolated in PDA media and incubated for seven days.Identification of Riau local $B$. bassiana was carried out macroscopically and microscopically based on its morphology using a book written by Barnett and Hunter [7].

Riau local isolates of B. bassiana growing on PDA media were isolated on crushed corn medium and incubated for five days. Starter B. bassiana broken corn was weighed according to treatment, namely $20 \mathrm{~g}, 25 \mathrm{~g}, 30 \mathrm{~g}, 35 \mathrm{~g}$ and $40 \mathrm{~g}$ respectively mixed with $1000 \mathrm{ml}$ of water then stirred and filtered. The suspension is put in a bottle and shaker for 24 hours. The suspension is then carried out dilution with a ratio of one $\mathrm{ml}$ of suspension and nine ml of water with a dilution of $10^{-7}$. Conidia were seen using a haemocytometer under a microscope and conidia density was calculated by handcounter. Conidia density is calculated by the formula:

$$
\mathrm{J}=\frac{\mathrm{t} \times \mathrm{d}}{0.25 \times \mathrm{n}} \times 10^{6}
$$

Where:

$\mathrm{J}$ : the number of spores in one gram of media

$\mathrm{t}$ : the number of spores in all the counted squares

$\mathrm{d}$ : dilution factor if it must be diluted $(\mathrm{d}=1$ means not diluted; $\mathrm{d}=10$ means diluted $1: 10)$

0. 25: kostanta

$\mathrm{n}$ : the number of squares counted 


\subsection{Application}

Riau local application of Riau local suspension B. bassiana was carried out using a $100 \mathrm{ml}$ sprayer. Each red chili plant is sprayed evenly according to the volume of spray. The application of Riau local suspension B. bassiana was carried out in the afternoon at $18.00 \mathrm{WIB}$.

\subsection{Data Analysis}

Daily mortality data were analyzed descriptively and displayed in the form of graphs, while the intensity of attack, red chili plant growth data were statistically analyzed using variance and displayed in tabular form. Data from variance was analyzed using Duncan's New Multiple Range Test (DNMRT) at 5\% level.

\section{Results}

\subsection{Daily Mortality (\%)}

The results of observations of the daily mortality percentage of $S$. litura larvae with the application of several different concentrations of Riau Riau local B. bassiana on red chili plants showed fluctuations in the mortality of $S$. litura larvae. Daily mortality fluctuations of $S$. litura after application of several concentrations of Riau local Riau B. bassiana can be seen in Figure 1.

\subsection{Attack intensity (\%)}

Application of concentration of Riau local entomopathogenic fungi B. bassiana on red chili significantly affected the intensity of attack of $S$. litura larvae (Table 1). The results of the DNMRT follow-up test at the $5 \%$ level can be seen in Table.

\subsection{Growth of red chili plants}

Application of concentration of Riau local entomopathogenic fungi B. bassiana in red chili has a significant effect on the growth of red chili plants. The results of the DNMRT follow-up test at the $5 \%$ level can be seen in Table 2 .

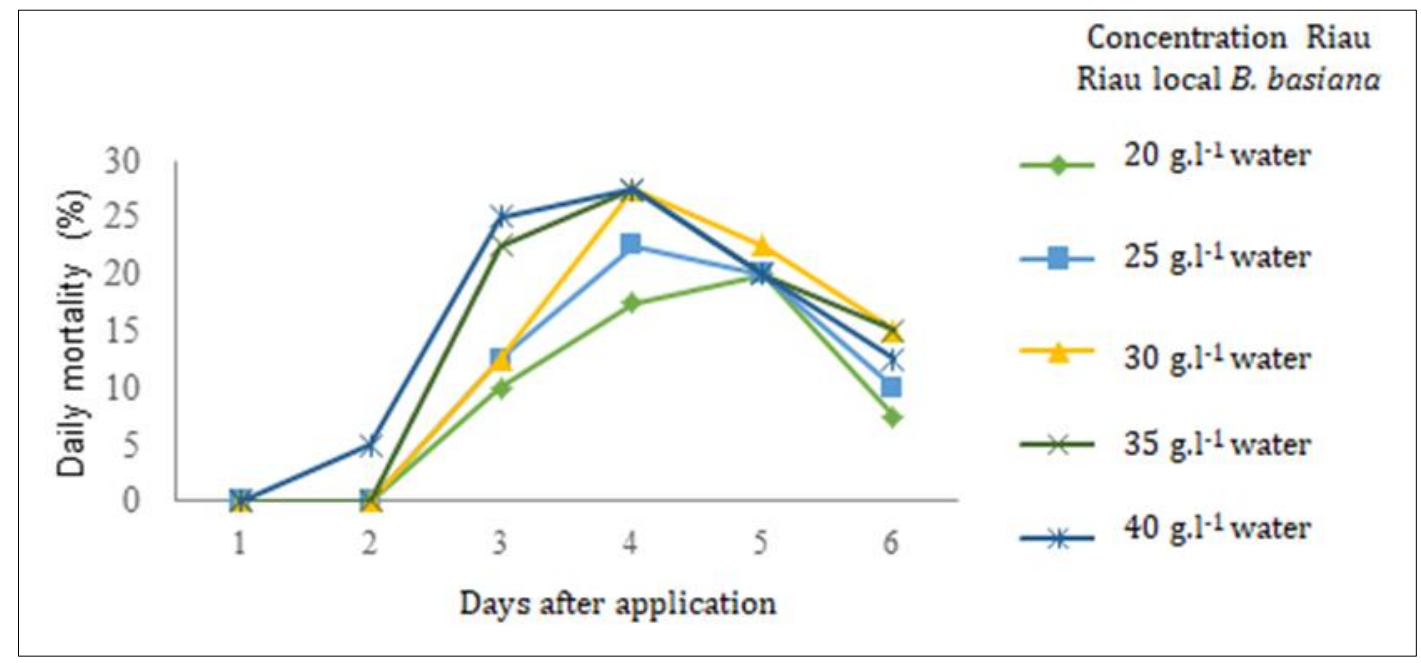

Figure 1 Daily mortality fluctuations of $S$. litura larvae after application of Riau Riau local B. bassiana on red chili plants 
Table 1 Attack intensity of S. litura pest on red chili plants after the application of of Riau Riau local B. bassiana

\begin{tabular}{|c|c|}
\hline Riau local concentrations of $B$. bassiana (conidia density) & Attack intensity (\%) \\
\hline 20 g.l $^{-1}$ air $\left(3,3 \times 10^{8}\right.$ kon.ml-1 $)$ & $41,63 \mathrm{a}$ \\
\hline 25 g..$^{-1}$ air $\left(3,8 \times 10^{8}\right.$ kon.ml-1) & $34,75 \mathrm{a}$ \\
\hline 30 g..$^{-1}$ air $\left(4,1 \times 10^{8}\right.$ kon.ml $\left.{ }^{-1}\right)$ & $4,15 \mathrm{~b}$ \\
\hline 35 g.l-1 air $\left(4,6 \times 10^{8}\right.$ kon.ml- $\left.{ }^{-1}\right)$ & $2,23 \mathrm{~b}$ \\
\hline 40 g.l-1 $\operatorname{air}\left(5,0 \times 10^{8}\right.$ kon.ml-1 $)$ & $2,23 \mathrm{~b}$ \\
\hline
\end{tabular}

The numbers in the row followed by lowercase are significantly different according to the DNMRT test at the $5 \%$ level.

Table 2 Growth of red chili plants after application of the of Riau Riau local B. bassiana

\begin{tabular}{|c|c|c|c|}
\hline $\begin{array}{l}\text { Riau local concentrations of } B \text {. } \\
\text { bassiana (conidia density) }\end{array}$ & $\begin{array}{l}\text { Plant Height } \\
\text { (cm) }\end{array}$ & $\begin{array}{l}\text { Dichotomous Height } \\
\text { (cm) }\end{array}$ & $\begin{array}{l}\text { Flowering } \\
\text { Age (days) }\end{array}$ \\
\hline 20 g.l -1 $^{-1}$ air $\left(3,3 \times 10^{8}\right.$ kon.ml-1 $)$ & $26,40 \mathrm{~d}$ & $14,12 \mathrm{c}$ & $41,0 \mathrm{a}$ \\
\hline 25 g.l-1 $\operatorname{air}\left(3,8 \times 10^{8}\right.$ kon.ml $\left.{ }^{-1}\right)$ & $33,55 \mathrm{c}$ & $15,37 \mathrm{~b}$ & $40,0 \mathrm{~b}$ \\
\hline 30 g.l-1 air $\left(4,1 \times 10^{8}\right.$ kon.ml $\left.{ }^{-1}\right)$ & $36,47 \mathrm{bc}$ & $16,87 \mathrm{a}$ & $39,5 \mathrm{bc}$ \\
\hline 35 g.l-1 air $\left(4,6 \times 10^{8}\right.$ kon.ml-1) & $39,37 \mathrm{ab}$ & $17,15 \mathrm{a}$ & $38,5 \mathrm{c}$ \\
\hline 40 g.l -1 $^{-} \operatorname{air}\left(5,0 \times 10^{8}\right.$ kon.ml- $\left.{ }^{-1}\right)$ & $41,57 \mathrm{a}$ & $17,75 \mathrm{a}$ & $37,0 \mathrm{~d}$ \\
\hline
\end{tabular}

The numbers in the row followed by lowercase are significantly different according to the DNMRT test at the $5 \%$ level.

\section{Discussion}

\subsection{Daily Mortality (\%)}

The first day after the application of Riau local B. bassiana no dead S. litura larvae were seen, presumably because Riau Riau local $B$. bassiana needed time to make contact with the larval integument and secreted beauvericin toxin which would damage the tissue and cause death of $S$. litura larvae. This is in accordance with the statement of Riningrum et al., [8] which states that B. bassiana takes 2-4 days to kill the test insects.

Daily mortality of S. litura larvae only occurred on the second day after application of 5\% according to the initial time of death for the first time, which was 43 hours after application (concentration 40 g.l-1 water). Concentration of Riau local B. bassiana 35 g.l-1 water, 30 g.l-1 water, 25 g.l-1 water, and 20 g.l-1 water on the second day after application has not been able to cause mortality in $S$. litura larvae. This is presumably because at this concentration the Riau local conidia density of $B$. bassiana applied was lower than the concentration of $40 \mathrm{gl}-1$ of water and the beauvericin toxin produced by Riau local $B$. bassiana was less, which resulted in the larval body of $S$. litura still being able to tolerate infection from B. bassiana. Riau locally so that the larvae can still survive. Prayogo [2] states that the tolerance response carried out by insects is an effort to defend their lives from pathogen attacks. Observations on the third day showed that all Riau local concentrations of $B$. bassiana caused the death of S. litura larvae. The daily mortality of Riau local $B$. bassiana at a concentration of $35 \mathrm{gl}-1$ water showed the percentage of dead $S$. litura larvae was $22.5 \%$, the concentration of $30 \mathrm{gl}-1$ water was $12.5 \%$, the concentration of $25 \mathrm{gl}-1$ water was $12.5 \%$ and concentration of 20 gl-1 of water by $10 \%$. The difference in the daily mortality percentage of $S$. litura larvae was caused by differences in the concentration of Riau local B. bassiana applied, the higher the Riau local B. bassiana concentration, the higher the infection power of $S$. litura larvae. Turnip et al., [9] stated that insect mortality is largely determined by the concentration applied, the higher the conidia density, the higher the mortality. 
Observation of the fourth day of daily mortality of $S$. litura larvae experienced the highest peak mortality of any Riau local $B$. bassiana concentration except the concentration of 20 g.l-1 water. The peak mortality of Riau local B. bassiana was 40 g.l-1 water, 35 g.l-1 water, 30 g.l-1 water was $27.5 \%$ and the concentration of 25 g.l-1 water was $22.5 \%$. The Riau local B. bassiana concentration of 20 g.l-1 only experienced an increase in daily mortality on the fifth day by $20 \%$. Riau local $B$. bassiana concentrations of 20 g.l-1 took longer to reach peak daily mortality than other Riau local $B$. bassiana concentrations. The difference in the peak time of death of $S$. litura larvae was due to differences in the concentration of Riau local $B$. bassiana applied to $S$. litura larvae so that the level of pathogenicity was also different. Mardiana [5] stated that the amount of concentration applied would determine the effectiveness of $B$. bassiana in controlling the test insects.

Application of various concentrations of Riau local B. bassiana caused a decrease in the percentage of daily mortality of $S$. litura larvae on the sixth day. Daily mortality fluctuations of $S$. litura larvae were caused because Riau local $B$. bassiana had infected and developed in the body of $S$. litura larvae by secreting toxins and absorbing body fluids of $S$. litura larvae which resulted in many $S$. litura larvae dying, so the number of $S$. litura larvae died. The litura that died the next day was reduced. The difference in daily mortality for each treatment was due to the different concentrations of entomopathogenic fungi that were applied to $S$. litura larvae so that their virulence was also different.

\subsection{Attack intensity (\%)}

Table 1 menunjukkan bahwa aplikasi Table 1 shows that the application of higher concentrations of Riau local Riau $B$. bassiana tends to cause the intensity of attack of $S$. litura larvae on red chili plants in the range of $2.23 \%-41.63 \%$. The concentration of $B$. bassiana in Riau local 30 gl-1 of water caused the intensity of attack of $4.15 \%$ and was significantly different from the concentration of 25 gl-1 of water and 20 gl-1 of water but not significantly different from the concentrations of $35 \mathrm{gl}-1$ of water and 40 gl-1 water.

The difference in pest attack intensity was caused by differences in the concentration of Riau local Riau B. bassiana which was applied to red chili plants. This was due to the activity of $S$. litura which was affected by infection with the fungi B. bassiana. S. litura pests that have been infected with the B. bassiana fungi will experience metabolic disorders, the respiratory system, and the digestive system, so that the armyworm's appetite is reduced resulting in the caterpillar becoming less active [4], so that the armyworm's activity will have an effect on the intensity of the damage did not increase.

Application of concentration of $B$. bassiana Riau local Riau 30 g.l-1 water, 35 g.l-1 water and 40 g.l-1 water can be classified as very low attack intensity because it is less than 10\%. This is in accordance with Syahrawi and Busniah [10] which states that the intensity of pest attacks can be categorized as very low if it is less than $10 \%$ and can be categorized as low if it is between $10-50 \%$.

\subsection{Growth of red chili plants}

Table 2 shows that the application of Riau local concentrations of B. bassiana on plant height parameters tends to cause higher chili plant height growth of $41.57 \mathrm{~cm}$. The concentration of 40 g.l-1 water had no significant effect with the concentration of 35 g.l-1 water but significantly different with the concentration of 30 g.l-1 water, 25 g.l-1 water, 20 g.l1 water. It is presumed that the higher the concentration of Riau local Riau B. bassiana applied, the higher the red chili plant height.

The dichotomous height parameter of the concentration of 30 g.l-1 water was not significantly different from the concentrations of 35 g.l-1 water and 40 g.l-1 water, but was significantly different with the concentrations of 20 g.l-1 water and 25 g.l-1 water. This is because the Riau local concentration of B. bassiana that is applied affects the growth of red chili plants. The higher the concentration of Riau local B. bassiana applied, the higher the dichotomous level.

Flowering age of red chili plants after application of Riau local Riau B. bassiana concentration ranged from 37-41 days. The concentration of 40 g.l-1 water was significantly different from other concentrations. because the higher the concentration of Riau local Riau B. bassiana applied, the faster the flowering period in chili plants. Concentration of 30 g.l-1 water showed no significant effect with concentrations of 35 g.l-1 water and 25 g.l-1 water. 


\section{Conclusion}

The Riau local Riau application B. bassiana within six days is able to caused the mortality of $S$. litura larvae by $90 \%$, attack intensity $2.23 \%$. The intensity of attack affects the growth of red chili plants, because low intensity can provide opportunities for red chili plants to grow optimally.

\section{Compliance with ethical standards}

\section{Acknowledgments}

The author would like to thank the Directorate of Research and Community Service, Ministry of Research and Higher Education of the Republic of Indonesia (KEMRISTEKDIKTI) (Contract number: 393/UN.19.5.1.3/PT 01.03/2020) for funding this research. This research is part of the Basic Research grant.

\section{Disclosure of conflict of interest}

All authors declare there is no conflict of interest in this paper.

\section{References}

[1] Riau Central Bureau of Statistics. Riau in Figures 2018. BPS Riau Province. Pekanbaru. 2018.

[2] Prayogo. Efforts to maintain the effectiveness of entomopathogenic fungi to control food crop pests. Journal of Agricultural Research and Development. 2006; 25(2): 47-54.

[3] Mulyono. Study of Pathogenicity of the Fungi Metarhizium anisopliae Against Pest Oryctes rhinoceros L. Coconut Plants in Various Application Techniques. Thesis of the Eleven Maret University Graduate Program. Surakarta. 2007.

[4] Nurani AR, IP Sudiarta, NN Darmiati. Test the effectiveness of the fungi Beauveria bassiana Bals. against armyworm ( Spodoptera litura F.) on tobacco plants. Journal of Tropical Agroecotechnology. 2018; 7(1): 11-23.

[5] Mardiana Y. Use of Multiple Concentrations of Beauveria bassiana Vuil. Riau locally to Control Maruca testualis in Long Bean (Vigna sinensis L) Plants. [Thesis]. Pekanbaru, Indonesia: Riau University. 2015.

[6] Steinhaus EA. Principles of Insect Pathology. McGRaw Hill Book Company. New York. 1969.

[7] Barnett HL, Hunterr. Illustrated Genera of Imperfect Fungi. Third Edition. Burgess Publishing Company. Minneapolis. Minnesota. 1972.

[8] Riningrum et al. Concentration test of the fungi Beauveria bassiana (Bals.) Vuill on mortality of pod ladybug (Riptortus linearis F.) in soybean plants. Indonesian Journal of Agricultural Sciences. 2020; 22(1): 9-15.

[9] Turnip A, DYP Runtuboi, D Loud. Test the effectiveness of the fungi Beauveria bassiana and application time against Spodoptera litura pests on mustard greens (Brassica juncea). Papuan Biology Journal. 2018; 10(1): 2631.

[10] Syahrawati MY, Busniah M. Insect Pests and Predators in the Generative Phase of Long Bean (Vigna sinensis (L.) Savi Ex Has) Plantation in Padang City. Agricultural Journal. Department of Plant Pests and Diseases. Faculty of Agriculture. Andalas University. field. 2009. 